\title{
Comparison of Work of Breathing Between Noninvasive Ventilation and Neurally Adjusted Ventilatory Assist in a Healthy and a Lung-Injured Piglet Model
}

\author{
Michelle L Jones DO, Shasha Bai PhD, Tracy L Thurman, Shirley J Holt RRT, \\ Mark J Heulitt MD, and Sherry E Courtney MD
}

\begin{abstract}
BACKGROUND: Noninvasive ventilation (NIV) is commonly used in neonates. A mode of NIV called neurally adjusted ventilatory assist (NAVA) offers patient-ventilator interactions by using electrical activity of the diaphragm to control mechanical breaths. We hypothesized that the work of breathing (WOB) would decrease with NIV-NAVA. Secondary objectives evaluated the impact of NIV-NAVA on arterial blood gases and respiratory parameters. METHODS: We compared WOB between synchronized breaths in NIV-NAVA and NIV in piglets with healthy lungs and then with surfactant-depleted lungs. Neonatal pigs (median, 2.0 [range, 1.8-2.4] kg) with healthy and then surfactant depleted lungs were sedated and ventilated with NIV-NAVA and NIV in random order. Airway flow and pressure waveforms were acquired. Waveforms were analyzed for the pressure-time product that reflected WOB. The primary outcome between modes was assessed with repeated measurement analysis of variance. RESULTS: The pressure-time product was significantly decreased for NIV-NAVA in both healthy and injured lungs $(P<.001) . \mathrm{P}_{\mathrm{aO}}, \mathrm{P}_{\mathrm{aCO}}$, inspiratory tidal volume, and peak inspiratory flow were not different in either model. CONCLUSIONS: Synchronized breaths during NIV-NAVA resulted in decreased WOB compared with synchronized breaths during NIV. Key words: neurally adjusted ventilatory assist; NAVA; noninvasive ventilation; work of breathing; NIV; respiratory physiology. [Respir Care 2018;63(12):1478-1484. (C) 2018 Daedalus Enterprises]
\end{abstract}

\section{Introduction}

Intubation and mechanical ventilation have significantly improved the survival rate of neonates. These treatments, however, are not without risk. Acute complications include air-leak syndromes, airway trauma, infection, and subglottic stenosis. ${ }^{1,2}$ Intubation and mechanical ventilation have also been shown to be associated with long-term risks, for example, bronchopulmonary dysplasia, ${ }^{3}$ and have been indicated as risk factors associated with retinopathy

Dr Jones, Dr Bai, Ms Thurman, and Dr Courtney are affiliated with Section of Neonatology, Department of Pediatrics, University of Arkansas for Medical Sciences, Little Rock, Arkansas. Dr Jones, Ms Holt, and Dr Courtney are affiliated with Section of Neonatology, Arkansas Children's Hospital, Little Rock, Arkansas. Dr Heulitt is affiliated with Division of Critical Care Medicine, Department of Pediatrics, Spence and Becky Wilson Baptist Children's Hospital, Memphis, Tennessee.

Financial support was provided by a Children's University Medical Group institutional grant. of prematurity. ${ }^{4,5}$ Currently, there is agreement that invasive mechanical ventilation should be minimized or avoided completely to reduce the risk of ventilator-induced lung injury. ${ }^{6}$ Use of noninvasive ventilation (NIV) in the preterm infant has been reported to reduce the need for intubation, decrease lung injury, and decrease the risk of

Dr Jones presented the data at the American Academy of Pediatrics
National Conference and Exhibition, held October 22-25, 2016, in San
Francisco, California; Hot Topics in Neonatology Conference, held De-
cember 5-7, 2016, in Washington DC; Diamond Conference, held April
28, 2017, in Little Rock, Arkansas.

The authors have disclosed no conflicts of interest.

Correspondence: Sherry E Courtney MD, Arkansas Children's Hospital, One Children's Way, Slot 512-5 Little Rock, AR 72202. E-mail: scourtney@uams.edu.

DOI: $10.4187 /$ respcare.06192 
long-term complications, for example, bronchopulmonary dysplasia. ${ }^{7,8}$

\section{See the Related Editorial on Page 1579}

Commonly used NIV strategies in the neonatal ICU include nasal CPAP and ventilation (NIV). Nasal CPAP applies a constant distending pressure level (above the atmospheric pressure level) during inhalation and exhalation to support spontaneously breathing neonates. NIV has a constant distending pressure with intermittent superimposed inflations. A recent meta-analysis compared NIV with CPAP and found that NIV decreases the need for intubation and reduces the incidence of extubation failure. ${ }^{9}$

Neurally-adjusted ventilator assist (NAVA) is a mode of assisted ventilation that uses the electrical activity of the diaphragm $\left(\mathrm{EA}_{\mathrm{di}}\right)$ to control the ventilator. The $\mathrm{EA}_{\mathrm{di}}$ represents the neural effort, both with respect to timing and amplitude. ${ }^{10,11}$ With NAVA ventilation, the $\mathrm{EA}_{\mathrm{di}}$ signal can trigger and cycle a positive-pressure breath independent of airway leak. ${ }^{10-12}$ NAVA can be used as an invasive form of ventilation as well as noninvasively (NIVNAVA). ${ }^{10,13}$ Improved synchrony with NAVA over NIV has been documented. ${ }^{14-16}$ However, to our knowledge, there are no data that indicate whether synchronized NIV-NAVA breaths may result in less work of breathing (WOB) than synchronized NIV breaths.

Our study used a piglet model. A number of studies have shown that the relative maturity of the piglet brain, lungs, and cardiovascular system is comparable with the human neonate. ${ }^{17-21}$ Eiby et $\mathrm{al}^{21}$ were able to further define similarities between piglets and humans at specific gestations. We hypothesized that WOB during synchronized breaths would be decreased with NIV-NAVA compared with NIV in both healthy and surfactant-depleted lungs in a piglet model. Our secondary objectives were to compare the effects of NIV-NAVA and NIV on arterial blood gases and respiratory parameters.

\section{Methods}

The animal review committee of the University of Arkansas for Medical Sciences approved this study. The work was conducted at Arkansas Children's Hospital Research Institute in Little Rock, Arkansas. The animals were cared for in accordance with the standards for care and use of laboratory animals set forth by the university. Twelve neonatal pigs were used for this evaluation. The pigs were male, domestic porcine anesthetized with a mixture of tiletamine, ketamine, and xylazine $(0.04 \mathrm{~mL} / \mathrm{kg})$ intramuscularly and Forane gas (Baxter Healthcare Corp, Deerfield, Illinois) (3-4\%) via mask (Canine Anesthesia Mask, Kent Scientific, Torrington, Connecticut). Dissection to

\section{QUICK LOOK}

\section{Current knowledge}

Because of the risks associated with invasive ventilation in a neonatal population, clinical practice is shifting to an emphasis on noninvasive ventilation (NIV) strategies in this subset of patients. NIV and neurallyadjusted ventilatory assist (NAVA) improve patientventilator synchrony when compared with other commonly used forms of neonatal NIV.

\section{What this paper contributes to our knowledge}

In a neonatal pig model, NIV-NAVA decreased the work of breathing during synchronous breaths when compared directly with synchronous breaths given with NIV. Decreased work of breathing was demonstrated in both healthy neonatal pig lungs and surfactant-depleted neonatal pig lungs.

the external jugular vein was performed and a central venous line placed for drug administration (dexmedetomidine $6-10 \mu \mathrm{g} / \mathrm{kg} / \mathrm{h}$ plus fentanyl $3-5 \mu \mathrm{g} / \mathrm{kg} / \mathrm{h}$ ) during the experiments. The level of sedation was clinically monitored to maintain the animal in a light sleep, defined as not moving but breathing spontaneously and with a consistent $\mathrm{EA}_{\mathrm{di}}$ tracing. In addition, an arterial catheter was placed in the carotid artery for blood gas and blood pressure monitoring.

Heart rate, oxygen saturation, and temperature were monitored with a physiologic monitor (SC $9000 \mathrm{XL}$, Siemens, Dräger, Germany). Each pig was randomized to NIVNAVA or NIV, and evaluated first in the healthy state and then again after lung injury. Thus, each pig was its own control for comparison between NIV-NAVA and NIV, and between healthy and surfactant depleted states so to minimize variability (Fig. 1). An $\mathrm{EA}_{\mathrm{di}}$ catheter was placed in all the pigs and remained in place throughout the experiment. The position of the $\mathrm{EA}_{\mathrm{di}}$ catheter was verified by using the position screen on the ventilator as well as the observation of the $\mathrm{EA}_{\mathrm{di}}$ signal itself. This position was monitored routinely throughout the study. Before any data collection, the position was confirmed in the same manner.

The pigs were ventilated (via mask) by using the Servo-i ventilator (Maquet, Getinge Group, Rastatt, Germany) with randomly applied NIV-NAVA and NIV with $3 \mathrm{~cm} \mathrm{H}_{2} \mathrm{O}$ PEEP and $\mathrm{F}_{\mathrm{IO}_{2}}$ of 1.0. In healthy porcine lungs, PEEP was optimized at $3 \mathrm{~cm} \mathrm{H}_{2} \mathrm{O}$ to avoid suppression of the respiratory drive. For NIV-NAVA, the median (range) set NAVA level was $0.4(0.3-0.5) \mathrm{cm} \mathrm{H}_{2} \mathrm{O} / \mu \mathrm{V}$ for the healthy lung and $0.5(0.3-1.0) \mathrm{cm}_{2} \mathrm{O} / \mu \mathrm{V}$ for the partially injured lung. The NAVA level was adjusted according to the $\mathrm{EA}_{\mathrm{di}}$ signal, similar to a clinical setting. Ac- 


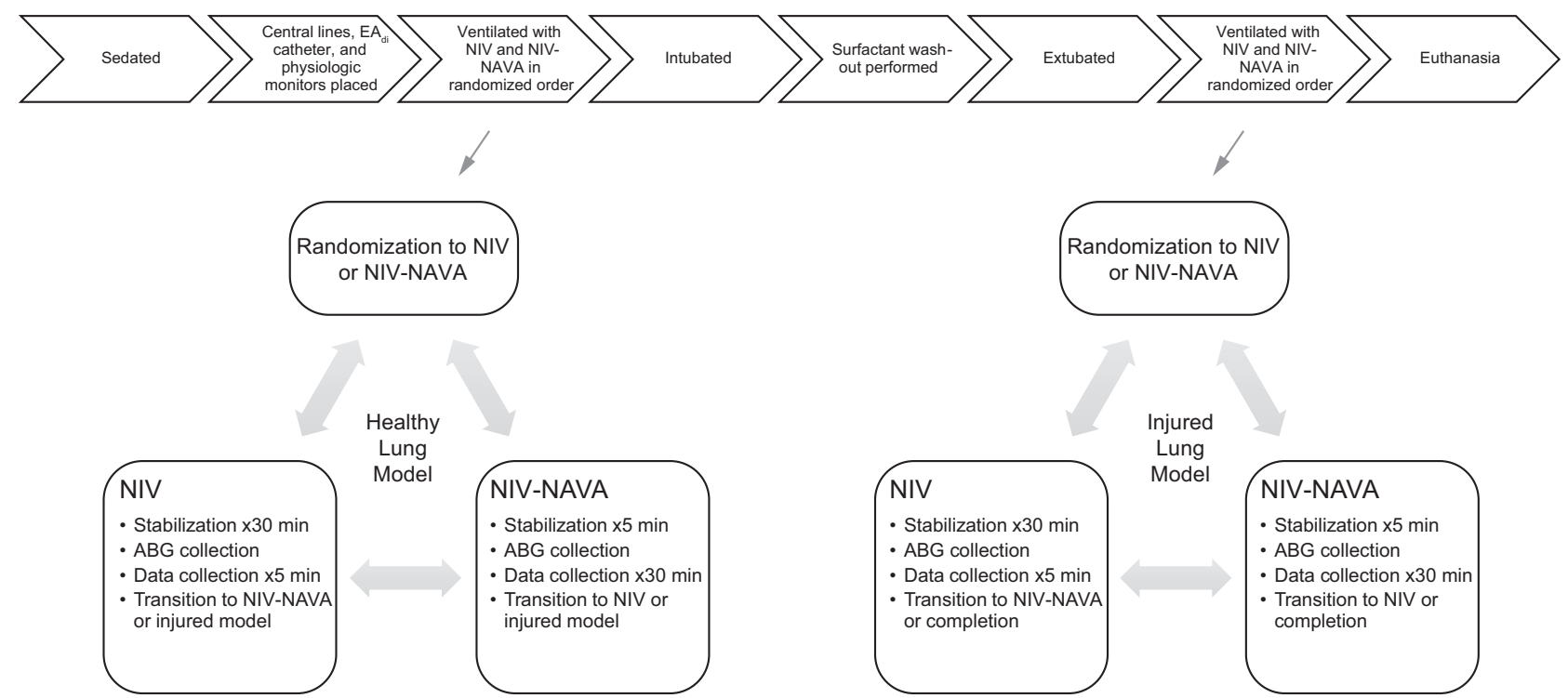

Fig. 1. Experimental setup. $E A_{d i}=$ electrical activity of the diaphragm; NIV = noninvasive ventilation; NAVA = neurally adjusted ventilatory assist; $A B G=$ arterial blood gas.

cording to the manufacturer of NAVA, the usual NAVA level is $0.5-2.0 \mathrm{~cm} \mathrm{H}_{2} \mathrm{O} / \mu \mathrm{V}$, with $\mathrm{EA}_{\mathrm{di}}$ signals between 5 and $15 \mu \mathrm{V}$. These parameters were used for adjustment of our study subject's NAVA level.

The set $\mathrm{EA}_{\mathrm{di}}$ trigger (median, range) was $0.5(0.2-$ $0.5) \mu \mathrm{V}$ for the healthy lung and $0.5(0.3-0.6) \mu \mathrm{V}$ for the partially injured lung. For NIV, pressure control was set to achieve a target tidal volume $\left(\mathrm{V}_{\mathrm{T}}\right)$ of $8-10 \mathrm{~mL} / \mathrm{kg}$, which is optimal in the piglet mode. For each mode of ventilation, a stabilization period of $30 \mathrm{~min}$ was followed by a 5-min data collection period. The pigs were then intubated with a 3.0 cuffed endotracheal tube and were ventilated on baseline settings; pressure control mode, target $\mathrm{V}_{\mathrm{T}}$ of $8-10 \mathrm{~mL} / \mathrm{kg}$, PEEP of $3 \mathrm{~cm} \mathrm{H}_{2} \mathrm{O}$ and $\mathrm{F}_{\mathrm{IO}_{2}}$ of 1.0. After $10 \mathrm{~min}$ of ventilation, an arterial blood gas sample was obtained to document $\mathrm{P}_{\mathrm{aO}_{2}}$, added together with $\mathrm{P}_{\mathrm{CO}_{2}}$ in the arterial blood $\left(\mathrm{P}_{\mathrm{aCO}_{2}}\right)$ of $>400 \mathrm{~mm} \mathrm{Hg}$; dynamic compliance was also documented.

To produce a partially injured lung model, the pigs were subject to a saline solution washout. ${ }^{22}$ The saline solution washout was completed with volumes of warm normal saline solution $(30 \mathrm{~mL} / \mathrm{kg})$ administered in $1-3$ instillations through a tight tracheal cannula via gravity drainage into and out of the lungs. Pigs were then ventilated with baseline settings for 5 min and dynamic compliance documented. Lungs were considered partially injured when compliance was $50-70 \%$ of baseline. The pigs were then extubated and ventilated (via mask) with randomly applied NIV-NAVA and NIV as with the healthy lung. We used a published method to set PEEP with a computerized conventional ventilation recruitment tool available on the Servo-i ventilator. ${ }^{23}$ The median (range) set PEEP was 5 (3-8) $\mathrm{cm} \mathrm{H}_{2} \mathrm{O}$ for the partially injured lung.
Measurements of respiratory flow and pressure waveforms were acquired by using the Biopac MP-100 System (Biopac Systems, Santa Barbara, California). A heated 0-35 L/min pneumotachograph (PNT) (Hans Rudolph, Shawnee, Kansas) was placed in line between the mask and the ventilator. Volume measurements were obtained through the computer by integrating the flow signal. Volume was verified with a calibrated syringe (Hans Rudolph). To monitor pressure, the pneumotachograph was equipped with a pressure hose, barb-type port that allowed airway pressure sampling. Pressure was calibrated with a manometer (Air Flow Developments, Wycombe, United Kingdom). All output signals were routed via an analog channel box into the Biopac MP100 data acquisition unit, which converted them into digital signals. Signals were obtained at a rate of 500 samples per second. Gas humidification was maintained by an in-line Fisher \& Paykel MR850 humidification system (Fisher \& Paykel, Irvine, California). Data were collected for each mode (NIV-NAVA and NIV) for both healthy and partially injured lungs. For each measurement period, there was a stabilization period of $30 \mathrm{~min}$, followed by data collection for $5 \mathrm{~min}$.

In the NIV mode, all breaths are pneumatically triggered. Flow and pressure waveforms obtained with the pneumotachograph at the airway were analyzed to identify evidence of subject-ventilator asynchrony. Flow asynchrony was determined by identifying the presence of concavity $\left(\geq 1 \mathrm{~cm} \mathrm{H}_{2} \mathrm{O}\right)$ in the pressure-time waveform during inspiration. ${ }^{24}$ Only synchronous breaths were analyzed. In the NIV-NAVA mode, breaths are either pneumatically triggered, which results in a pressure support breath, or neurally triggered. NAVA is triggered on a firstcome-first-served basis between a neural signal, which is 


\section{WOB DURING NIV vs NIV-NAVA}

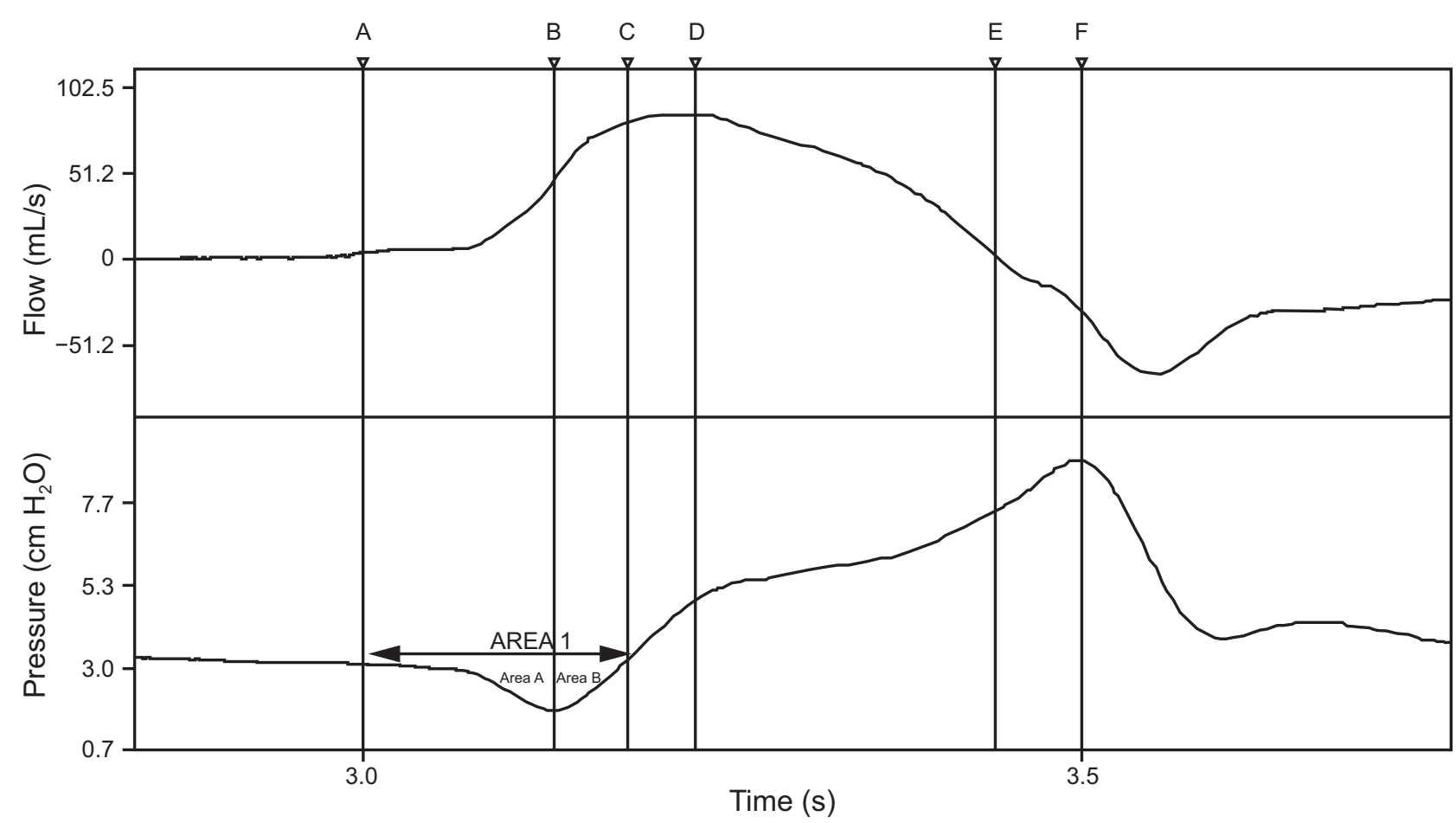

Fig. 2. Graphic representation of pressure-time product (PTP) measurements by using a representative breath from a study piglet. The $x$ axis is the time in seconds; $y$ axis is the flow in $\mathrm{mL} / \mathrm{s}$ and pressure in $\mathrm{cm} \mathrm{H}_{2} \mathrm{O}$. (A) Zero flow, initiation of the breath; (B) point at which the ventilator begins pressurization; $(C)$ point at which pressure returns to baseline; (D) peak inspiratory flow; (E) end of inspiration; $(F)$ peak inspiratory pressure. PTP area A = Integration of pressure from point A to B, which represents patient's work of breathing (WOB) (the effort by the patient during triggering); PTP area $B=$ integration of pressure from point $B$ to point $C$, which represents both patient and ventilator WOB; PTP area $1=$ area A plus area B (points A to C). PTP area 1 reflects the amount of effort expended to activate a mechanical breath. PTP area 2, from points $C$ to $D$, represents the work performed by the ventilator.

determined by a deflection in the $\mathrm{EA}_{\mathrm{di}}$ signal, and a pneumatic trigger, which is caused by a deflection in airway pressure. Maximum pressure that can be achieved in NIVNAVA is $30 \mathrm{~cm} \mathrm{H}_{2} \mathrm{O}$. Classification of breaths was determined via video recording of the ventilator screen during experiments. Trigger indication is displayed in the message/alarm field of the screen of the ventilator and is displayed as a pneumatic or neural trigger for each breath. Breaths from the video recording of the ventilator screen were matched timewise to breaths collected from the pneumotachograph at the airway opening and documented as pneumatically or neurally triggered for $1 \mathrm{~min}$. Only neurally triggered synchronous breaths were analyzed.

Pressure waveforms were analyzed for pressure-time product (PTP), as a measure of WOB. PTP area A was defined as the area of the pressure curve (integration of pressure with respect to time) from initiation of a breath (zero flow) to the beginning of ventilator pressurization (most negative deflection of pressure). PTP area A reflects the subject's WOB or the work required for the subject to trigger a breath. PTP area $\mathrm{B}$ was defined as the area of the pressure curve from the beginning of ventilator pressurization (most negative deflection of pressure) to return to baseline pressure. PTP area B reflects both subject and ventilator work, or the work needed for the subject and the ventilator to complete a breath that has already been initiated. PTP area 1 is area A and area B combined. PTP area 1 reflects the effort of the subject to trigger a breath as well as the initial work performed by both the subject and the ventilator. A graphic depiction can be seen in Figure 2.

Flow and pressure waveforms were analyzed for inspiratory $\mathrm{V}_{\mathrm{T}}$, peak inspiratory flow, and peak pressure. Inspiratory $\mathrm{V}_{\mathrm{T}}$ was recorded rather than expiratory $\mathrm{V}_{\mathrm{T}}$ due to the inherent nature of leaks with NIV. Inspiratory $V_{T}$, peak inspiratory flow, peak pressure, and PTP were measured for 10 neurally triggered breaths for NIV-NAVA and 10 synchronous breaths for NIV. Asynchronous breaths for any mode were excluded from the analysis. Arterial blood gases were analyzed by using $i$-STAT (Abbott, Princeton, New Jersey), a blood gas analyzer system. Primary outcomes of interest were $\mathrm{P}_{\mathrm{aO}_{2}}(\mathrm{~mm} \mathrm{Hg})$ and $\mathrm{P}_{\mathrm{aCO}}$ $(\mathrm{mm} \mathrm{Hg})$. Blood gas samples were collected for both NIV and NIV-NAVA modes after the 5-min data collection period with both the healthy and partially injured lung. Mean arterial blood pressure $(\mathrm{mm} \mathrm{Hg}$ ) and heart rate (beats/min) were monitored continuously with a physiologic monitor (SC 9000XL, Siemens, Dräger Medical, Telford, Pennsylvania). Breathing frequency (f), $\mathrm{EA}_{\mathrm{di}}$ peak 


\section{WOB DURING NIV vs NIV-NAVA}

$(\mu \mathrm{V})$, mean $\mathrm{EA}_{\mathrm{di}}(\mu \mathrm{V})$, leak fraction $(\%)$, and dynamic compliance $\left(\mathrm{mL} / \mathrm{cm} \mathrm{H}_{2} \mathrm{O}\right)$ were downloaded from the ventilator.

Each outcome was summarized as mean \pm SD separately by lung status and mode of ventilation. PTP areas between the modes of ventilation were assessed by repeated

Table 1. Comparisons of PTP Area A, PTP Area B, and PTP Area 1 Between Modes of Ventilation (NIV and NIV-NAVA) by Lung Status

\begin{tabular}{cccc}
\hline \hline Lung & NIV-NAVA & NIV & $P^{*}$ \\
\hline Healthy & & & \\
PTP area A $\dagger$ & $0.035 \pm 0.027$ & $0.059 \pm 0.014$ & $<.001$ \\
PTP area B $\ddagger$ & $0.025 \pm 0.020$ & $0.041 \pm 0.018$ & $<.001$ \\
PTP area 1§ & $0.061 \pm 0.044$ & $0.100 \pm 0.028$ & $<.001$ \\
Injured & & & \\
PTP area A & $0.045 \pm 0.026$ & $0.069 \pm 0.031$ & $<.002$ \\
PTP area B & $0.031 \pm 0.022$ & $0.040 \pm 0.024$ & .11 \\
PTP area 1 & $0.076 \pm 0.042$ & $0.109 \pm 0.044$ & $<.003$ \\
& & &
\end{tabular}

$\overline{\text { Data are presented as }}$ mean $\pm \mathrm{SD}$.

* Repeated measures analysis of variance.

$\dagger$ Subject's work to trigger mechanical breath.

\$ Subject and ventilator work of breathing.

$\S$ Area A plus Area B, the amount of effort expended to activate a mechanical breath. $\mathrm{PTP}=$ pressure-time product

PTP area $\mathrm{A}=$ area of the pressure curve (integration of pressure with respect to time) from initiation of a breath (zero flow) to the beginning of ventilator pressurization (most negative deflection of pressure)

PTP area $\mathrm{B}=$ area of the pressure curve from the beginning of ventilator pressurization (most negative deflection of pressure) to return to baseline pressure

PTP area $1=$ area $\mathrm{A}$ and area $\mathrm{B}$ combined

$\mathrm{NIV}=$ noninvasive ventilation

NAVA $=$ neurally adjusted ventilatory assist measurement analysis of variance models in healthy and injured lung models separately. Secondary outcomes (f, leak fraction, peak $\mathrm{EA}_{\mathrm{di}}$, mean $\mathrm{EA}_{\mathrm{di}}$ mean, heart rate, $\mathrm{P}_{\mathrm{aO}}, \mathrm{P}_{\mathrm{aCO}}$, inspiratory $\mathrm{V}_{\mathrm{T}}$, peak inspiratory flow, and peak pressure) were similarly assessed. Statistical significance was defined as $P<$.05. All statistical analyses were performed with Stata v 14.2 (StataCorp, College Station, Texas).

\section{Results}

The 12 pigs weighed a mean (range) of $2.0(1.8-2.4)$ $\mathrm{kg}$. There was a significant difference in PTP area A, area $\mathrm{B}$, and area 1 between NIV-NAVA and NIV in both lung models, as seen in Table 1 and Figure 3. There was no difference in $\mathrm{P}_{\mathrm{aO}_{2}}, \mathrm{P}_{\mathrm{aCO}_{2}}$, inspiratory $\mathrm{V}_{\mathrm{T}}$, and peak inspiratory flow. Peak pressure was statistically higher in the NIV-NAVA group in both healthy and injured lungs. The $\mathrm{EA}_{\mathrm{di}}$ peak was not different between the groups, although it was nearly significant in the healthy lung. The median (range) dynamic compliance was 1.9 (1.3-2.2) $\mathrm{mL} / \mathrm{cm} \mathrm{H}_{2} \mathrm{O}$ for healthy lung (baseline) and $1.0(0.7-1.4) \mathrm{mL} / \mathrm{cm} \mathrm{H}_{2} \mathrm{O}$ for the partially injured lung. There was no difference in $\mathrm{f}$, heart rate, or mean arterial blood pressure between the groups. There was also no difference in leak fraction or mean $\mathrm{EA}_{\mathrm{di}}$. These results are shown in Table 2.

\section{Discussion}

Our study demonstrated that WOB in synchronous breaths, as measured by PTP, was significantly less for NIV-NAVA breaths versus NIV breaths in both the healthy

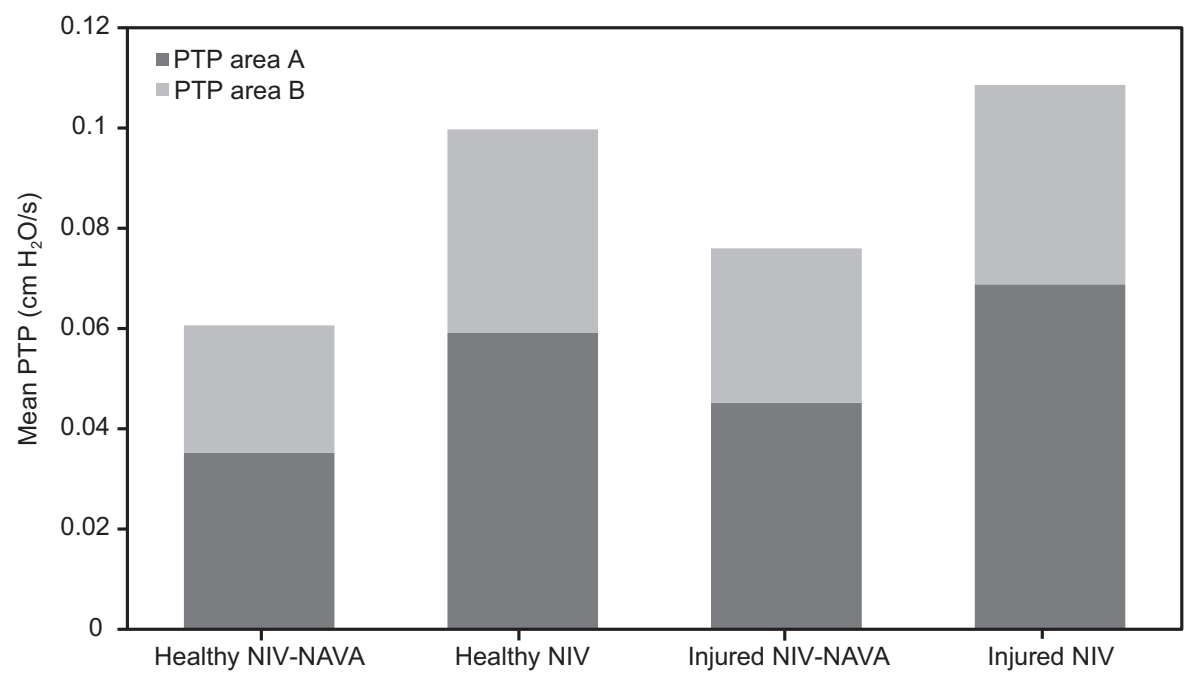

Fig. 3. Histogram of mean pressure-time product (PTP) measurements for each mode of ventilation in the healthy and injured lung models. The height of the bar graph represents PTP area 1 (sum of area A and area B). See Figure 1 and text for details. For the healthy lung, area $\mathrm{A}$, area $\mathrm{B}$, and area 1 are all significant at $P<.001$, noninvasive ventilation (NIV) and neurally adjusted ventilatory assist (NAVA) vs NIV. For the injured lung: Area $A, P=.002$; area $B, P=.11$; and area $1, P=.003$, NIV-NAVA vs NIV. Analysis of variance was used for repeated measures. 
Table 2. Secondary Outcome Measures

\begin{tabular}{|c|c|c|c|}
\hline Lung & NIV-NAVA & NIV & $P^{*}$ \\
\hline \multicolumn{4}{|l|}{ Healthy } \\
\hline $\begin{array}{l}\text { Frequency, } \\
\text { breaths/min }\end{array}$ & $66 \pm 10$ & $60 \pm 12$ & .18 \\
\hline Leak fraction $\%$ & $24 \pm 15$ & $24 \pm 19$ & .98 \\
\hline Peak $\mathrm{EA}_{\mathrm{di}}, \mu \mathrm{V}$ & $5.5 \pm 2.2$ & $6.8 \pm 3.3$ & .049 \\
\hline Mean $\mathrm{EA}_{\mathrm{di}}, \mu \mathrm{V}$ & $0.7 \pm 0.3$ & $0.7 \pm 0.4$ & .62 \\
\hline Heart rate, beats/min & $133 \pm 30$ & $135 \pm 31$ & .75 \\
\hline $\begin{array}{l}\text { Mean arterial blood } \\
\text { pressure, } \mathrm{mm} \mathrm{Hg}\end{array}$ & $85 \pm 11$ & $86 \pm 9$ & .71 \\
\hline $\mathrm{P}_{\mathrm{aO}_{2}}, \mathrm{~mm} \mathrm{Hg}$ & $459 \pm 68$ & $427 \pm 59$ & .21 \\
\hline $\mathrm{P}_{\mathrm{aCO}_{2}}, \mathrm{~mm} \mathrm{Hg}$ & $40 \pm 5$ & $42 \pm 6$ & .23 \\
\hline Inspiratory $\mathrm{V}_{\mathrm{T}}, \mathrm{mL}$ & $23 \pm 6$ & $23 \pm 5$ & .66 \\
\hline Peak inspiratory flow, $\mathrm{mL} / \mathrm{s}$ & $118 \pm 32$ & $112 \pm 25$ & .66 \\
\hline Peak pressure, $\mathrm{cm} \mathrm{H}_{2} \mathrm{O}$ & $9 \pm 2$ & $8 \pm 1$ & .044 \\
\hline \multicolumn{4}{|l|}{ Injured } \\
\hline $\begin{array}{l}\text { Frequency, } \\
\text { breaths/min }\end{array}$ & $72 \pm 17$ & $74 \pm 14$ & .60 \\
\hline Leak fraction $\%$ & $19 \pm 20$ & $22 \pm 18$ & .29 \\
\hline Peak $\mathrm{EA}_{\mathrm{di}}, \mu \mathrm{V}$ & $7.4 \pm 3.5$ & $8.2 \pm 3.5$ & .27 \\
\hline Mean $\mathrm{EA}_{\mathrm{di}}, \mu \mathrm{V}$ & $1.3 \pm 1.3$ & $1.1 \pm 0.9$ & .42 \\
\hline Heart rate, beats/min & $168 \pm 58$ & $166 \pm 47$ & .83 \\
\hline $\begin{array}{l}\text { Mean arterial blood } \\
\text { pressure, } \mathrm{mm} \mathrm{Hg}\end{array}$ & $79 \pm 10$ & $85 \pm 8$ & .07 \\
\hline $\mathrm{P}_{\mathrm{aO}_{2}}, \mathrm{~mm} \mathrm{Hg}$ & $331 \pm 158$ & $289 \pm 167$ & .28 \\
\hline $\mathrm{P}_{\mathrm{aCO}_{2}}, \mathrm{~mm} \mathrm{Hg}$ & $46 \pm 7$ & $47 \pm 8$ & .65 \\
\hline Inspiratory $\mathrm{V}_{\mathrm{T}}, \mathrm{mL}$ & $23 \pm 9$ & $20 \pm 5$ & .08 \\
\hline Peak inspiratory flow, $\mathrm{mL} / \mathrm{s}$ & $138 \pm 50$ & $132 \pm 41$ & .48 \\
\hline Peak pressure, $\mathrm{cm} \mathrm{H}_{2} \mathrm{O}$ & $13 \pm 4$ & $12 \pm 2$ & .03 \\
\hline \multicolumn{4}{|l|}{$\begin{array}{l}\text { Data are presented as mean } \pm \mathrm{SD} \text {. } \\
* \text { Repeated measures analysis of variance. } \\
\mathrm{NIV}=\text { noninvasive ventilation } \\
\mathrm{NAVA}=\text { neurally adjusted ventilatory assist } \\
\mathrm{EA}_{\mathrm{di}}=\text { electrical activity of the diaphragm } \\
\mathrm{V}_{\mathrm{T}}=\text { tidal volume }\end{array}$} \\
\hline
\end{tabular}

and injured lung. WOB, in general terms, represents an assessment of the afterload on the respiratory muscles or opposition to their contraction. ${ }^{25}$ One common way of measuring WOB uses an esophageal balloon to measure esophageal pressure. This method of measuring WOB relies on pressure and volume changes but cannot accurately measure WOB when there is ineffective respiratory effort. PTP more closely approximates energy expenditure of the respiratory muscles. ${ }^{26}$ PTP estimates the metabolic cost of breathing and quantifies inspiratory effort. ${ }^{27-29}$ PTP evaluates energy expenditure during both isometric and nonisometric contraction. ${ }^{27,29}$ PTP is calculated by integrating pressure and time for the duration of contraction of the respiratory muscles.

Lee et $\mathrm{al}^{14}$ showed that NIV-NAVA improved patientventilator synchrony and diaphragmatic unloading in preterm infants in comparison with NIV, despite large air leaks. Chen et $\mathrm{al}^{30}$ demonstrated that NIV-NAVA improves patient-ventilator synchrony and reduces diaphragmatic muscle load and WOB in preterm infants in comparison with NIV. ${ }^{30}$ Beck et al ${ }^{16}$ summarized 15 studies in pediatric subjects and demonstrated improved patient-ventilator interaction with NAVA, whether invasive or noninvasive, compared with conventional modes. To our knowledge, our study was the first to show that the WOB with the synchronous breaths of NIV-NAVA was less than that of synchronous breaths that may occur with NIV.

These findings were likely explained because $\mathrm{EA}_{\mathrm{di}}$ signal allows more or less support with each breath, depending on patient demand. For NIV, support is not patient driven; breaths are set by the operator with regard to timing and pressure, and are consistent with each breath. Thus, the operator makes a "best guess" as to the support required by the patient. With NIV, increased patient demand results in more flow delivery but not more pressure. With NIV-NAVA, the patient can demand and receive higher pressures, and also has the option to take sigh breaths with variable inspiratory times, which allow better lung recruitment. These factors likely decrease WOB in synchronized NIV-NAVA breaths compared with NIV breaths, even if the NIV breaths are synchronized with the baby's breathing pattern. An elevated $\mathrm{EA}_{\mathrm{di}}$ signal represents patient demand for increased respiratory support.

Lee et al showed a decrease in peak pressure with NIVNAVA compared with non-invasive pressure support. ${ }^{14}$ In our study, we found peak pressure to be statistically higher in the NIV-NAVA group; however, the difference was very small and likely not clinically important. In addition, there were no decreases in $\mathrm{f}$, heart rate, or mean arterial blood pressure, whereas significant differences in the WOB were found. Our study time period may have been too short to detect decreases in peak pressure that may have occurred over time, or changes in $\mathrm{f}$, heart rate, or mean arterial blood pressure. WOB is difficult to assess during NIV. Use of esophageal balloons and calibrated pneumotachography is cumbersome and time consuming. PTP is an estimate of the WOB but is not possible if interaction with the ventilator does not occur. In our study, it was very important to note that WOB was not analyzed in asynchronous breaths. Thus, overall WOB may vary and must be evaluated by other means. Clearly, it is important to know that the synchronized breaths that occur with NIVNAVA result in decreased WOB compared with NIV under the best of circumstances (synchrony).

\section{Study Limitations}

This was an animal model study performed in a controlled laboratory environment and, as such, may not directly translate to the neonatal population and ICUs. Also, as noted, we did not analyze the WOB in asynchronous breaths. If patients have long stretches of backup ventila- 


\section{WOB DURING NIV vs NIV-NAVA}

tion during NIV-NAVA, which accompanied increases in asynchronous breathing, could result in increased WOB even if NIV-NAVA is the set mode. Piglets needed to be lightly sedated to perform the study; sedation may have influenced the results, although using each piglet as its own control should have provided consistency.

\section{Conclusions}

In the piglet model, synchronous breaths delivered with NIV-NAVA resulted in decreased WOB in both healthy and surfactant depleted lungs when compared with synchronous breaths during NIV. Further trials of NIV-NAVA in neonates are warranted.

\section{REFERENCES}

1. Badiee Z, Nekooie B, Mohammadizadeh M. Noninvasive positive pressure ventilation or conventional mechanical ventilation for neonatal continuous positive airway pressure failure. Int J Prev Med 2014;5(8):1045-1053.

2. Miller JD, Carlo WA. Pulmonary complications of mechanical ventilation in neonates. Clin Perinatol 2008;35(1):273-281, x-xi.

3. Rojas-Reyes MX, Lozano JM, Solà I, Soll R. Overview of ventilation strategies for the early management of intubated preterm infants (Protocol). Cochrane Database Syst Rev 2015;(4):CD011663.

4. Mitsiakos G, Papageorgiou A. Incidence and factors predisposing to retinopathy of prematurity in inborn infants less than 32 weeks of gestation. Hippokratia 2016;20(2):121-126.

5. Hwang JH, Lee EH, Kim EA. Retinopathy of prematurity among very-low-birth-weight infants in Korea: incidence, treatment, and risk factors. J Korean Med Sci 2015;30(Suppl 1):S88-S94.

6. Committee on Fetus and Newborn. Respiratory support in preterm infants at birth. Pediatrics 2014;133(1):171-174.

7. Vendettuoli V, Bellù R, Zanini R, Mosca F, Gagliardi L, Italian Neonatal Network). Changes in ventilator strategies and outcomes in preterm infants. Arch Dis Child Fetal Neonatal Ed 2014;99(4):F321-F324.

8. Bancalari E, Claure N. The evidence for non-invasive ventilation in the preterm infant. Arch Dis Child Fetal Neonatal Ed 2013;98(2): F98-F102.

9. Lemyre B, Davis PG, De Paoli AG, Kirpalani H. Nasal intermittent positive pressure ventilation (NIPPV) versus nasal continuous positive airway pressure (NCPAP) for preterm neonates after extubation. Cochrane Database Syst Rev 2017;2:CD003212.

10. Stein H, Beck J, Dunn M. Non-invasive ventilation with neurally adjusted ventilatory assist in newborns. Semin Fetal Neonatal Med 2016;21(3):154-161.

11. Stein H, Firestone K. Application of neurally adjusted ventilatory assist in neonates. Semin Fetal Neonatal Med 2014;19(1):60-69.

12. Beck J, Brander L, Slutsky AS, Reilly MC, Dunn MS, Sinderby C. Non-invasive neurally adjusted ventilatory assist in rabbits with acute lung injury. Intensive Care Med 2008;34(2):316-323.

13. Sinderby C, Beck J. Neurally adjusted ventilatory assist in noninvasive ventilation. Minerva Anestesiol 2013;79(8):915-925.
14. Lee J, Kim HS, Jung YH, Shin SH, Choi CW, Kim EK, et al. Non-invasive neurally adjusted ventilatory assist in preterm infants: a randomised phase II crossover trial. Arch Dis Child Fetal Neonatal Ed. 2015;100(6):F507-513.

15. Kallio M, Koskela U, Peltoniemi O, Kontiokari T, Pokka T, SuoPalosaari M, Saarela T. Neurally adjusted ventilatory assist (NAVA) in preterm newborn infants with respiratory distress syndrome-a randomized controlled trial. Eur J Pediatr 2016;175(9):1175-1183.

16. Beck J, Emeriaud G, Liu Y, Sinderby C. Neurally adjusted ventilatory assist (NAVA) in children: a systematic review. Minerva Anestesiol 2016;82(8):874-883.

17. Schmid G, Pfitzer P. Mitoses and binucleated cells in perinatal human hearts. Virchows Arch B Cell Pathol Incl Mol Pathol 1985; 48(1):59-67.

18. Pond WG, Boleman SL, Fiorotto ML, Ho H, Knabe DA, Mersmann $\mathrm{HJ}$, et al. Perinatal ontogeny of brain growth in the domestic pig. Proc Soc Exp Biol Med 2000;223(1):102-108.

19. Williams SM, Sullivan RK, Scott HL, Finkelstein DI, Colditz PB, Lingwood BE, et al. Glial glutamate transporter expression patterns in brains from multiple mammalian species. Glia 2005;49(4):520-541.

20. Björkman ST, Miller SM, Rose SE, Burke C, Colditz PB. Seizures are associated with brain injury severity in a neonatal model of hypoxia-ischemia. Neuroscience 2010;166(1):157-167.

21. Eiby YA, Wright LL, Kalanjati VP, Miller SM, Bjorkman ST, Keates HL, et al. A pig model of the preterm neonate: anthropometric and physiological characteristics. PLoS One 2013;8(7):e68763.

22. Lachmann B, Robertson B, Vogel J. In vivo lung lavage as an experimental model of the respiratory distress syndrome. Acta Anaesthesiol Scand 1980;24(3):231-236.

23. Hanson A, Göthberg S, Nilsson K, Larsson LE, Hedenstierna G. VTCO2 and dynamic compliance-guided lung recruitment in surfactant-depleted piglets: a computed tomography study. Pediatr Crit Care Med 2009;10(6):687-692.

24. Nilsestuen JO, Hargett KD. Using ventilator graphics to identify patient-ventilator asynchrony. Respir Care 2005;50(2):202-234; discussion 232-234.

25. Heulitt M, Courtney S. Pediatric and Neonatal Mechanical Ventilation: From Basics to Clinical Practice. Heidelberg: Springer; 2015: 338-340.

26. Heulitt M, Courtney S. Pediatric and Neonatal Mechanical Ventilation: From Basics to Clinical Practice. Heidelberg: Springer; 2015: 346-348.

27. Collett PW, Perry C, Engel LA. Pressure-time product, flow, and oxygen cost of resistive breathing in humans. J Appl Physiol 1985; 58(4):1263-1272.

28. McGregor M, Becklake MR. The relationship of oxygen cost of breathing to respiratory mechanical work and respiratory force. J Clin Invest 1961;40:971-980.

29. Field S, Sanci S, Grassino A. Respiratory muscle oxygen consumption estimated by the diaphragm pressure-time index. J Appl Physiol Respir Environ Exerc Physiol 1984;57(1):44-51.

30. Chen Z, Luo F, Ma XL, Lin HJ, Shi LP, Du LZ. Application of neurally adjusted ventilatory assist in preterm infants with respiratory distress syndrome [in Chinese with English abstract]. Zhongguo Dang Dai Er Ke Za Zhi. 2013;15(9):709-712.

This article is approved for Continuing Respiratory Care Education credit. For information and to obtain your CRCE

(free to AARC members) visit www.rcjournal.com

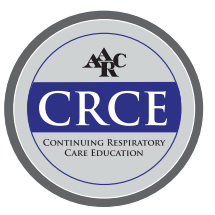

